
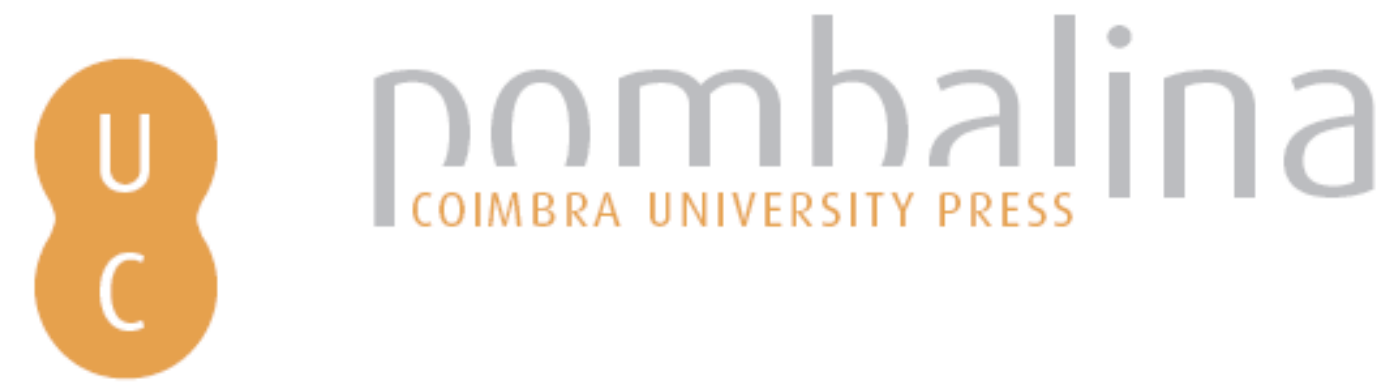

\title{
Ao sabor da sintaxe, a que sabe a tradição?: contribuição para o estudo do património linguístico da alimentação
}

Autor(es): $\quad$ Corrêa-Cardoso, João; Loureiro, Ana Paula

Publicado por: Imprensa da Universidade de Coimbra; Annablume

URL

persistente: URI:http://hdl.handle.net/10316.2/39621

DOI: $\quad$ DOI:https://doi.org/10.14195/978-989-26-1191-4_12

Accessed : $\quad$ 26-Apr-2023 08:57:47

A navegação consulta e descarregamento dos títulos inseridos nas Bibliotecas Digitais UC Digitalis, UC Pombalina e UC Impactum, pressupõem a aceitação plena e sem reservas dos Termos e Condições de Uso destas Bibliotecas Digitais, disponíveis em https://digitalis.uc.pt/pt-pt/termos.

Conforme exposto nos referidos Termos e Condições de Uso, o descarregamento de títulos de acesso restrito requer uma licença válida de autorização devendo o utilizador aceder ao(s) documento(s) a partir de um endereço de IP da instituição detentora da supramencionada licença.

Ao utilizador é apenas permitido o descarregamento para uso pessoal, pelo que o emprego do(s) título(s) descarregado(s) para outro fim, designadamente comercial, carece de autorização do respetivo autor ou editor da obra.

Na medida em que todas as obras da UC Digitalis se encontram protegidas pelo Código do Direito de Autor e Direitos Conexos e demais legislação aplicável, toda a cópia, parcial ou total, deste documento, nos casos em que é legalmente admitida, deverá conter ou fazer-se acompanhar por este aviso.

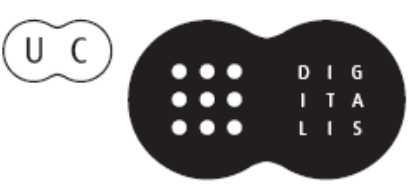




\title{
Ao SABOR DA SINTAXe, A QUE SABE A TRAdiçÃo? \\ ConTRIBUiçÃo PARA O ESTUdO DO PATRIMÓNIO \\ LINGUÍSTICO DA ALIMENTAÇÃO \\ The syntax of taste, how does tradition taste? \\ Contribution to the study of food linguistic heritage
}

\author{
Jỗo CorrêA-Cardoso \\ Universidade de Coimbra, \\ Faculdade de Letras, Celga-Iltec, $\mathrm{CECH}$ \\ cardo@gmail.com \\ Ana Paula Loureiro \\ Universidade de Coimbra, \\ Faculdade de Letras, Celga-Iltec \\ olivelou@gmail.com
}

Resumo: A história da alimentação faz-se sobretudo nas (e pelas) narrativas que, sobre este tópico, vamos construindo nos textos que partilhamos, no âmbito das práticas comunicativas quotidianas. É nosso objetivo, nesta primeira incursão exploratória sobre o tema, apresentar alguns dados sobre a ocorrência de determinados sintagmas nominais que veiculam o tópico "alimentação tradicional portuguesa" em textos representativos da atual variedade europeia da língua. Tendo em conta que o estatuto sintático e semântico na frase de uma expressão referencial determina e reflete o seu lugar também no texto e na construção da sua macroestrutura temática e informativa, com profundas implicações identitárias no longo processo de narração e de institucionalização da nossa memória coletiva, pretendemos, em concreto, identificar os comportamentos sintáticos de expressões referenciais do campo semântico das tradições alimentares, a saber: cozinha tradicional portuguesa, comida tradicional portuguesa, receitas tradicionais portuguesas e pratos tradicionais portugueses. A base de análise é constituída por dados linguísticos atestados num corpus do português contemporâneo. Foram consideradas apenas estruturas frásicas, entendida a frase como a unidade nuclear da construção da informação e da dinâmica do texto.

Palavras-chave: alimentação; património linguístico; organização sintática e semântica da informação; tópico.

AвstRACT: Food history takes places mainly in (and through) the narratives about this theme, which we build, in the texts we share, in the scope of everyday communicative practices. It is our objective, in this first exploratory incursion in this theme, to present some data about the occurrence of noun phrases which convey the topic of "traditional Portuguese food" in representative texts of the current European variety of the language. Taking into account that the semantic and syntactic role at 
the sentence level of a referential expression determines and reflects its place both in the text and in the construction of its thematic and informative macrostructure, with profound identity implications throughout the process of narration and institutionalisation of our collective memory, we intend, in particular, to identify syntactic behaviours of referential expressions in the semantic field of traditional foods, namely: traditional Portuguese cooking, traditional Portuguese food, traditional Portuguese recipes and traditional Portuguese dishes. The analytical approach is constituted by linguistic data attested in a corpus of contemporary Portuguese. Only phrasal structures were considered in this study, wherein a sentence is perceived as a nuclear unit for the construction of information and text dynamic.

KEYwords: food, linguistic heritage, syntactic and semantic organisation of information, theme.

\section{Memórias do palato COMUM}

O ciclo da produção, da seleção e da preparação do que se come, conducente aos atos de partilha dos alimentos, envolveu sempre dinâmicas sociais, aspetos culturais e construções simbólicas basilares em todas as sociedades humanas ${ }^{1}$. Tais alicerces comunitários complexificam-se quando duas ou mais comunidades linguísticas se encontram e verbalizam, nas suas línguas de origem ou em terceiras vias de comunicação verbal - entretanto frutos dessas reuniões civilizacionais -, as experiências humanas vividas através e/ ou a propósito dos consumos alimentares.

Muito para além da mera satisfação de uma necessidade natural e, portanto, universal para a espécie humana ${ }^{2}$, ou da relação que o Homem estabelece com o meio ambiente, estão, assim, as arquiteturas gastronómicas que preservam os valores das heranças e das tradições gustativas que (i) vão sinalizando, no devir histórico, as fronteiras identitárias entre os grupos, (ii) aferem, de modo contínuo, os pesos simbólicos da comunhão alimentar e (iii) orientam, até esteticamente, o refinamento dos prazeres suscitados pela degustação. Dito de forma diversa, consumir alimentos consiste, cada vez

${ }^{1}$ Nas sociedades ocidentais, não esqueçamos a importância da forte mescla da espiritualidade judaico-cristã e da filosofia helénica, presente na simbologia da refeição ou do banquete.

${ }^{2}$ Por razões de natureza temática (e de tempo e espaço), não nos deteremos em questões pertinentes que igualmente afetam a vida humana mas de modo disfórico. Referimo-nos, por exemplo, ao fenómeno da fome ou das consequências nefastas desencadeadas por consumos clinicamente desaconselhados. Registamos, porém, que na investigação médica, antropológica e forense mais recente, este último tema está a ser motivo de um ímpeto editorial considerável que equaciona a combinação de hábitos alimentares, de padrões de vida e de valores comportamentais e éticos que resulta na chamada morbimortalidade. O combate aos dois fenómenos referidos é agora encarado, por exemplo, como (i) um exercício de cidadania ou como (ii) um aspeto da segurança nacional ou ainda como (iii) a trave da sustentabilidade e do desenvolvimento humano. 
mais nas sociedades contemporâneas, em manter, no sentido antropológico mais estrito, a sociabilidade que, por seu turno, assegura - em moldes práticos e simbólicos - a coesão do grupo e a sua projeção no futuro.

Por outro lado, se o ato de ingerir os alimentos aproxima os seus atores, não poderemos dissociá-lo das experiências sensoriais e das (inter)subjetividades por ele convocadas e que impulsionam o exercício do(s) afeto(s) e, inclusivamente, têm inspirado nas Belas Artes, na Música e na Literatura a elaboração fictícia de universos, em que a comida ou (a própria sugestão de) $o$ ato de deglutir contribuem decisivamente para a marcação de ambientes psicossociológicos e culturais díspares. A título ilustrativo, atentemos no seguinte trecho de uma autora portuguesa, em que à autenticidade dos elementos contextuais da refeição se associam os traços essenciais para a renovação da existência humana - não apenas, claro está, na vertente física, mas sobretudo na dimensão anímica:

Esta cozinha, esta copa, este cheirinho a molho de carne e ervas, esta mesa posta, a toalha de riscas largas, cinzentas e salmão, a sericaia no aparador, o queijo, as azeitonas, o pão de mistura, dão-me uma fome adolescente, como não sentia há anos. Penso confusamente que não é preciso muito para ser feliz, é só ver a vida pelo lado simples, pelo lado alegre, e lembro-me da última refeição em casa dos meus pais, o coq au vin tão carregado de rancores e barreiras e complicações, a última ceia de que o velho Téo saiu crucificado e um novo Téo ressuscitou. ${ }^{3}$

Se a História da Cultura é, em dimensões plurais, devedora do fenómeno da alimentação, há, porém, coordenadas recentes que podem vir a perturbar a sedimentação tranquila de marcas pertinentes quer na elaboração dos gostos, quer na composição das identidades, quer ainda na gestão da simbólica coletiva. Referimo-nos às preocupações gradualmente generalizadas com a saúde e, mais especificamente, com o aspeto físico do corpo humano (que, aliás, também se consome ${ }^{4}$ ), e à internacionalização dos poderes económicos que vai neutralizando apetências e práticas alimentares através da implementação, por exemplo, de cadeias de restaurantes de comida rápida em locais diversos no nosso planeta.

${ }^{3}$ Faria 2007: 39. Anotem-se os ecos da espiritualidade judaico-cristã na enumeração das etapas da Paixão de Cristo, em que o próprio nome do protagonista - Téo - nos recorda Jesus.

${ }^{4}$ A propósito, basta pensarmos em determinadas expressões das gírias e do calão do tipo «Ele é um pão/um pãozinho!»; «Aquela rapariga loura é uma lasca!»; «És podre de bom!»; «És boa como o milho!»; «Comia-te toda!» que nos permitem estabelecer, por seu turno, conexões entre a alimentação e o erotismo. A bibliografia dedicada a esta velha conexão na cultura humana é extensa. 


\section{As práticas verbais e as práticas alimentares}

Algumas correntes filosóficas antigas já defendiam que apenas através da palavra dita o objeto observado era apreendido e recebia o estatuto de entidade autónoma. Hoje, com o contributo das ciências da linguagem e da cognição, sabemos que a multiplicidade organizativa do pensamento advém do património acumulado de experiências de cada indivíduo com a sua realidade próxima, articulado com o do grupo em que se inscreve. As experiências comunitárias, dotadas de um amplo lastro histórico e imagético - e expressas pela língua comum -, sistematizam-se em esquemas representacionais que, por sua vez, se integram em ideologias e, assim, na qualidade de fortes instrumentos de domínio e de interpretação do mundo, lideram a eterna procura do significado e a legitimação das relações sociais e culturais.

A consciência aguda das modificações pessoais e coletivas, produzidas sob os auspícios de tais comportamentos internos de cada um de nós, tem sido reconhecida pelas muitas áreas do saber humano e igualmente explicitada nas artes. Mais uma vez, recorramos ao discurso literário:

One thing I was beginning to feel, and that was that I could never again be quite the same man I had been. (...) I had learned to look more closely at life as it was lived, to recognize that there were such things as facts in the world, to emerge from the realm of mind and idea and to place certain values on the concrete and objective phases of existence. ${ }^{5}$

$\mathrm{Na}$ constituição das representações da alimentação que aqui nos ocupa, a rede semiótica intrincada resulta dos imensos vetores implicados nas fases de apreensão, de análise e de reconstituição cultural do fenómeno, pelo que as representações nunca poderão ser entendidas como estáticas ${ }^{6}$. Ora, é justamente por causa desta movência que, no âmbito do presente estudo, utilizaremos apenas exemplos do português europeu contemporâneo - que nos é sincrónico, estatuto idêntico de que goza também a parametrização epocal por nós vivida e que condiciona a delimitação semântica das expressões selecionadas.

A dimensão comunicativa do manuseamento da comida e das práticas alimentares do quotidiano é, então, bem ampla, pois, como vemos, abarca o que materialmente se consome e a imaterialidade de que esse ato se faz eco. Se o leitor se recorda, as expressões referenciais do campo semântico que selecionámos iniciam-se pelos itens «cozinha», «comida», «receitas»e "pratos», isto é, por resultados lexicais que advêm da aplicação de filtros linguístico-culturais

\footnotetext{
${ }^{5}$ London 2000, 102-103.

${ }^{6}$ Cf. Halliday 1978 e Davsky 2005.
} 
sobre a matéria-prima - sobre os alimentos - que se transforma, de acordo com as normas específicas da gastronomia de cada comunidade. A aquisição das referidas normas decorre durante toda a nossa vida e é acompanhada, em paralelo, por outras aprendizagens semióticas que vão da apresentação dos alimentos confecionados e à escolha dos locais da refeição, à elaboração dos sistemas de hierarquias entre as próprias refeições e às regras especiosas de conduta à $\mathrm{mesa}^{7}$. De igual modo, se herdam e transmitem as opiniões e juízos, as crenças, os sentimentos, as atitudes e muitos mais segmentos de avaliação do objeto e que constituem, afinal, as linhas estruturantes das representações de que há pouco falávamos.

Por esta razão, todos recorremos às representações (da alimentação e de quaisquer outros objetos da realidade que nos são fundamentais) para construirmos a nossa identidade - para sermos reconhecidos como pares e/ ou como indivíduos diferentes -, para renegociar aspetos identitários nos processos de aculturação implicados nos encontros de culturas e de línguas diversas ${ }^{8}$, para mantermos a memória social do grupo e, em última análise, para pensarmos o mundo 9 e para exercermos direitos essenciais à espécie humana como são, por exemplo, o direito à sensibilidade e o direito à transcendência - que encontram, também no campo concreto da fruição gustativa, os domínios (inspiradores) das suas realizações.

\section{Dinâmica das ReferênCIAS: (Re)CONSTRUÇÃo discursiva dos OBJETOS DE DISCURSO}

Numa perspetiva linguístico-discursiva, a (re)construção dos objetos de discurso (Mondada \& Dubois 1995 e 2003, Koch 2001 e 2008; Marcuschi 2001; Apothéloz \& Reicher, apud Koch 2008) deve ser vista como um processo (con)textualmente localizado e resultante de uma quádrupla dinâmica

${ }^{7} \mathrm{O}$ mesmo acontece no universo discursivo dos livros de cozinha pessoais que circulam nas famílias. A imprecisão na referência às quantidades dos ingredientes utilizados, o menor rigor na explicitação das técnicas de manuseamento dos preparados, a indisciplina na indicação dos tempos de preparação e de cozeduras são só aparentes. As experiências vividas comunitariamente, os gostos formados ao longo do tempo e as pequenas subtilezas dos saberes técnicos nos processos de processamento da comida preenchem os espaços que nos parecem lacunares com toda a informação histórica partilhada - e, por isso, comum - que não valerá a pena verbalizar por ser tida como há muito presente na construção da identidade do grupo e das suas mundivisões. A este propósito, leiam-se os seguintes textos: Algranti 2002, Jovchelovitch 2007, Long 2004, Marks 2005 e Sutton 2001.

${ }^{8}$ Como sabemos, o fenómeno da chamada globalização veio acelerar o ritmo em que se processam estes encontros.

${ }^{9}$ «É por isso que se pode dizer que comer é também uma forma de conhecer. Desde que se coma inteligentemente; humanisticamente, diria Montaigne.» (Gallian 2007: 180, o sublinhado é nosso). 
interacional: (i) entre os sujeitos, (ii) entre o(s) sujeito(s) e o real, (iii) entre $o(\mathrm{~s})$ sujeito(s) e o texto e (iv) entre o texto e o real.

Distanciados já, de um certo ponto de vista, das realidades extralinguísticas que descrevem e categorizam, os objetos de discurso são, assim, e antes de mais, produto de compromissos - dinâmicos - entre a(s) visão(-ões) subjetiva(s) e o mundo. E, neste sentido, podem ser vistos - em conjunto com as escolhas dos processos de (cor)referenciação (e a tessitura textual que daí resulta) - como indicadores da intencionalidade do sujeito, de um "querer-dizer" que está muito para além das coisas, mas também muito para além das palavras e do texto.

Por outro lado, já no plano concreto do texto, estes objetos, enquanto elementos (mais ou menos) ativos e (mais ou menos) relevantes da rede e da progressão das representações textuais, são também entidades complexas, "depositárias" das memórias do texto ${ }^{10}$. Neste sentido, a interpretação de um qualquer objeto de discurso é indissociável - na medida dos movimentos de ativação, reativação e desativação - das interpretações de outros objetos e sentidos com os quais convive, mais ou menos diretamente, no universo do texto. É assim que a interpretação de uma ocorrência, por exemplo, do sintagma cozinha tradicional portuguesa, num contexto como Comecemos pelo restaurante D. Tonho, está na moda, sem dúvida, e pertence ao famoso Rui Veloso. Ai, para além da cozinha tradicional portuguesa e de um serviço perfeito, pode ter a sorte de esbarrar-se com o cantor portuense. (R1235), tem de ter em conta os sentidos de outros sintagmas que com ele coocorrem no contexto anterior e posterior, mais ou menos distante, nomeadamente, moda, serviço perfeito, entre outros. As relações de coocorrência - de diversa ordem, e num sentido muito lato - devem, assim, ser entendidas como elementos determinantes para a (re)construção e interpretação dos objetos de discurso.

No nível mais circunscrito da unidade frase $^{11}$, unidade comunicativa por excelência, importa observar também de que modo estes objetos de discurso integram a rede de relações sintáticas e semânticas instituída primariamente pelo verbo e secundariamente por outros núcleos alinhados na hierarquia frásica. Podemos, assim, dizer que o percurso da (re)construção das representações concetuais pode ser reconstituído a partir das interações sintáticas e semânticas que estabelecem na frase, do estatuto que nelas assumem e da distância a que ficam quer do(s) núcleo(s) da frase, quer de outros espaços centrais do ponto de vista sintático e/ou textual-informativo.

${ }^{10}$ Koch 2008, fala de introdução do objeto na memória textual.

${ }^{11}$ Entendemos por frase o enunciado que contém no mínimo um verbo, os seus eventuais argumentos, possíveis adjuntos e outros elementos de outros planos. Para este e outros conceitos de análise sintática, veja-se Raposo et al. 2013. 
Ao sabor da sintaxe, a que sabe a tradição? Contribuição para o estudo do património linguístico da alimentação

\section{Apresentação do corpus utilizado}

Hoje em dia, é indiscutível a pertinência dos corpora linguísticos eletrónicos no estudo das línguas naturais, uma vez que fornecem aos investigadores acervos com dimensões gigantescas e possibilidades inéditas de exploração da matéria verbal aí conservada que, em termos ideais, é constantemente atualizada pelas respetivas equipas gestoras ${ }^{12}$. Para o nosso trabalho de teor descritivo dos comportamentos sintáticos de determinadas expressões referenciais do campo semântico das tradições alimentares em Portugal (cozinha tradicional portuguesa, comida tradicional portuguesa, receitas tradicionais portuguesas e pratos tradicionais portugueses), elegemos o comummente designado CRPC.

O Corpus de Referência do Português Contemporâneo é um vasto repositório de 311,4 milhões de palavras ilustrativas da realidade linguística do português europeu, africano, asiático e do português do Brasil ${ }^{13}$. Produto científico do Centro de Linguística da Universidade de Lisboa, teve início em 1988 e surgiu como um projeto de trabalho que ampliaria os materiais (apenas orais) já coligidos no Português Fundamental.

Dando-se primazia às fontes escritas, cobre-se o período compreendido entre meados do século XIX e o ano de 2006, intensificando-se a recolha de dados a partir de 1970. Esta vertente do projeto ${ }^{14}$ contribui em 309, 8 milhões de palavras, obtidas a partir da análise de produções escritas muito heterogéneas: de textos literários e didáticos; de obras científicas e técnicas; de textos jornalísticos e de panfletos; de atas do parlamento português.

Este Corpus tem constituído um apoio inestimável à investigação científica no âmbito das Ciências da Linguagem quer em Portugal, quer no estrangeiro e foi, por exemplo, angular na elaboração do Dicionário da Lingua Portuguesa Contemporânea, publicado pela Academia das Ciências de Lisboa ${ }^{15}$.

${ }^{12}$ Para um estudo das linguísticas de corpus, ler, entre outros textos, Habert, Nazarenko e Salem 1997.

${ }^{13}$ Para se conhecerem, de modo sistematizado, alguns aspetos da história dos corpora linguísticos (portugueses e europeus) e das potencialidades que promovem na investigação linguística, cf. Bacelar do Nascimento et al. 1996, Bacelar do Nascimento et al. 2000, Bacelar do Nascimento, 2000 e 2003.

${ }^{14}$ No $C R P C$, há ainda um acervo de 1,6 milhões de palavras obtidas a partir de registos orais, atualizados em contextos informais e formais que foram gravados e transcritos.

${ }^{15}$ Para a obtenção de informações mais detalhadas sobre (i) a equipa de investigadores, (ii) a organização dos trabalhos, (iii) a configuração do $C R P C$ e (iv) o seu contributo para a elaboração do pensamento científico nesta área de inquirição linguística em Portugal, cf. www.clul.ul.pt/pt/ recursos/183-reference-corpus-of-contemporary-portuguese-crpc. Para efetuar uma pesquisa exploratória, cf. alfclul.clul.ul.pt (CRPC Portugal only v2.3). 


\section{ANÁLISE DE DADOS: PERFIL SINTÁTICO-SEMÂNTICO DAS OCORRÊNCIAS}

As expressões referenciais cozinha tradicional portuguesa, comida tradicional portuguesa, receitas tradicionais portuguesas e pratos tradicionais portugueses registam um total de 18 ocorrências diferentes no corpus. O SN cozinha tradicional portuguesa é o sintagma que apresenta mais ocorrências (10, excluindo os que representam títulos de livros), seguindo-se o sintagma comida tradicional portuguesa, com 5 casos. Os sintagmas receitas tradicionais portuguesas e pratos tradicionais portugueses apresentam um número residual de casos: 1 e 2 ocorrências, respetivamente. Todos os casos aqui considerados correspondem a contextos frásicos.

É nosso objetivo, como referimos, traçar o perfil sintático-semântico e textual-informativo das ocorrências, no CRPC, destes sintagmas. Em concreto, procuraremos dados relativos aos seguintes indicadores de comportamento:

(i) Estrutura do sintagma: constituição interna;

(ii) Função desempenhada pelo SN e núcleo da relação (verbal ou nominal);

(iii) Nível frásico de ocorrência: frase principal ou oração subordinada;

(iv) Posição (distância hierárquica) relativamente ao núcleo da frase;

(v) Natureza semântica típica do núcleo da relação;

(vi) Natureza semântica típica das adjetivações diretas ou próximas;

(vii) Natureza semântica típica das redes referenciais em que os $\mathrm{SN}$ se integram.

\section{Perfil de comportamento na frase: constituição interna}

Os sintagmas nominais em análise são maioritariamente do tipo determinado definido. Há um caso de um sintagma indefinido ( $\underline{\text { uma nova cozinha }}$ tradicional portuguesa) e 5 casos de sintagmas reduzidos (como é o caso de pesquisa de receitas tradicionais portuguesas).

$\mathrm{Na}$ tabela, resumem-se os dados numéricos relativos a este parâmetro:

\begin{tabular}{|l|c|c|c|c|c|}
\hline Sintagma $\downarrow$ & Tipo $\rightarrow$ & $\begin{array}{c}\text { SN com artigo } \\
\text { definido }\end{array}$ & $\begin{array}{c}\text { SN com artigo } \\
\text { indefinido }\end{array}$ & $\begin{array}{c}\text { SN } \\
\text { reduzido }\end{array}$ & Totais \\
\hline $\begin{array}{l}\text { Cozinha tradicional } \\
\text { portuguesa }\end{array}$ & 8 & 1 & 1 & 10 \\
\hline $\begin{array}{l}\text { Comida tradicional } \\
\text { portuguesa }\end{array}$ & 3 & & 2 & 5 \\
\hline $\begin{array}{l}\text { Receitas tradicionais } \\
\text { portuguesas }\end{array}$ & 1 & & 1 & 1 \\
\hline $\begin{array}{l}\text { Pratos tradicionais } \\
\text { portugueses }\end{array}$ & 12 & 1 & 1 & 2 \\
\hline Totais & & & & & 18 \\
\hline
\end{tabular}

Tabela 1 - Perfil de comportamento na frase: constituição interna 


\section{Perfil de comportamento na frase: função e núcleo}

Do ponto de vista do estatuto sintático desempenhado pelos SN na frase, começámos por agrupar as ocorrências tendo em conta quer o núcleo de que dependem, quer a função que desempenham na relação. Distinguimos, assim, dois grupos de ocorrências: (i) casos em que os sintagmas estão na dependência de um verbo e respetivas funções; e (ii) casos em que os sintagmas dependem de nome (aqui identificados globalmente como SP de N, sem distinção entre complementos e modificadores). Para os dois grupos, distinguimos ainda dois níveis de ocorrência: nível de frase e nível de oração subordinada.

A tabela que se segue resume os números desta tipologia:

\begin{tabular}{|l|c|c|c|c|c|c|c|c|}
\hline Sintagma & Função $\rightarrow$ & SU & CD & COBL & $\begin{array}{c}\text { ADJ } \\
\text { ADV }\end{array}$ & $\begin{array}{c}\text { SP } \\
\text { de N }\end{array}$ & Outra & Totais \\
\hline & Nível $\downarrow$ & & & & & & & \\
\hline $\begin{array}{l}\text { Cozinha tradicional } \\
\text { portuguesa }\end{array}$ & Frase & & 1 & & 1 & 4 & & 6 \\
\hline Totais & Or. sub. & & 1 & & 1 & 2 & & 4 \\
\hline $\begin{array}{l}\text { Comida tradicional } \\
\text { portuguesa }\end{array}$ & Frase & 1 & 1 & 1 & & & 1 & 4 \\
\hline & Or. sub. & & & & & 1 & & 1 \\
\hline Totais & & 1 & 1 & 1 & & 1 & 1 & 5 \\
\hline $\begin{array}{l}\text { Receitas tradicionais } \\
\text { portuguesas }\end{array}$ & Frase & & & & & 1 & & 1 \\
\hline & Or. sub. & & & & & & & \\
\hline Totais & & & & & & 1 & & 1 \\
\hline $\begin{array}{l}\text { Pratos tradicionais } \\
\text { portugueses }\end{array}$ & Frase & & 1 & & & & & 1 \\
\hline & Or. sub.. & & 1 & & & & & 1 \\
\hline Totais & & & 2 & & & & & 2 \\
\hline Totais & & 1 & 5 & 1 & 2 & 8 & 1 & 18 \\
\hline
\end{tabular}

Tabela 2 - Perfil de comportamento na frase: função e núcleo.

O conjunto dos dados numéricos obtidos merece-nos algumas reflexões, de que destacamos as seguintes:

$1^{\circ}$. O número de ocorrências destes sintagmas em posição dependente de verbo ( 9 casos) e o número de ocorrências na dependência de nome são sensivelmente idênticos: respetivamente, 9 e 8 casos $(8+1$, se considerarmos a ocorrência em enumeração explicativa de nome).

$2^{\circ}$ Com o estatuto de modificador/complemento de nome (introduzido sempre pela preposição de), os SN podem ocorrer em diferentes níveis na hierarquia da estrutura frásica ou oracional, mais ou menos distantes do 
núcleo verbal. Ao nível superior de frase (5 casos), os sintagmas ocorrem principalmente (4 dos 5 casos) inseridos em espaços argumentais (Sujeito, CD e Predicativo de Sujeito). Nestes contextos de ocorrência, ocupam habitualmente posições tendencialmente mais distantes do núcleo. Sejam os seguintes exemplos, ora ao nível de frase, ora ao nível de oração subordinada:

noCOD_1059017: Hernâni Machado é [um cultor(1º) seguro e conhecedor da cozinha tradicional portuguesa $\left.\left(2^{\circ}\right)\right]$.

noCOD_1046440: O "chef” José Arménio, natural de Arcos de Valdevez, comanda a casa há oito anos e [dá continuidade $\left(1^{\circ}\right)$ a um trabalho $\left(2^{\circ}\right)$ de pesquisa $\left(3^{\circ}\right)$ histórica de receitas tradicionais portuguesas $\left(4^{\circ}\right)$ ] iniciada pelo seu antecessor, resgatando uma série de pratos antigos da cozinha lusitana e da doçaria conventual. J0033: Esta planta, lembre-se, [desempenha $\left(1^{\circ}\right)$ um papel $\left(2^{\circ}\right)$ essencial no tempero $\left(3^{\circ}\right)$ dos maranhos, burulhões ou borlhões $\left(4^{\circ}\right)$, um dos espécimes $\left(5^{\circ}\right)$ mais originais da cozinha tradicional portuguesa $\left(6^{\circ}\right)$ ], infelizmente afastados das ementas dos restaurantes, mesmo da sua região de origem, que é a Beira Interior.

noCOD_1025841: Para este responsável, “a organização desta exposição mundial [parece ignorar $\left(1^{\circ}\right)$ a existência das confrarias báquicas e gastronómicas, não lhes pedindo $\left(2^{\circ}\right)$ sequer opinião $\left(3^{\circ}\right)$ sobre o modo de $\operatorname{ser}\left(4^{\circ}\right)$ do, por certo existente, pavilhão $\left(5^{\circ}\right)$ da cozinha tradicional portuguesa $\left.\left(6^{\circ}\right)\right]^{\prime \prime}$.

$3^{\circ}$. Por outro lado, em contexto de dependência de verbo, os sintagmas assumem essencialmente funções de complemento direto ( 5 casos), ora de frase, ora de oração subordinada. Estes casos ocorrem na dependência dos verbos ter (2), incluir (2) e servir (1). Sejam exemplos:

J106423: O Tavares, que se quer manter como uma referência de luxo na gastronomia nacional, terá no cardápio, essencialmente, uma "nova cozinha tradicional portuguesa", que será da responsabilidade do chefe Joaquim Figueiredo, proveniente do restaurante Bica do Sapato.

noCOD_1070417: E se incluir os pratos tradicionais portugueses

"recauchutados" nas ementas das selecções possa ser tarefa difícil, a intenção do chefe de cozinha da selecção nacional portuguesa Hélio Loureiro era servir de anfitrião aos colegas dos outros países, numa iniciativa pioneira que muito agradou aos "colegas de profissão e rivais no jogo".

40 Em 3 dos 8 casos atestados no corpus com o estatuto de SP de N, o sintagma surge nitidamente com o papel de "objeto", complemento dos nomes cultor, apreciador e pesquisa, o que aproxima este tipo de ocorrências do subgrupo destes SN com função de CD.

$5^{\circ}$. Sobressai ainda, neste conjunto de dados, o valor residual das ocorrências com estatuto de sujeito - registámos apenas um caso: 
Ao sabor da sintaxe, a que sabe a tradição? Contribuição para o estudo do património linguístico da alimentação

noCOD_1045432: Na zona destinada à restauração marcam presença a comida tradicional portuguesa, a gastronomia italiana, doçaria, gelataria e um salão de chá, situado num dos espaços do antigo palácio.

$6^{\circ}$. No seu conjunto, constatámos que os $\mathrm{SN}$ ocorrem sobretudo ao nível superior de frase (12 dos 18 casos).

\section{Perfil de comportamento na frase: verbos e nomes de que dependem}

Considerámos nesta secção alguns dados relativos aos itens lexicais com os quais os SN considerados estabelecem relações de dependência.

Em contexto de relação com o verbo, estes sintagmas coocorrem, (i) em posição de complemento, com os verbos ter, servir, incluir e gostar, (ii) em posição de sujeito, com a expressão verbal marcar presença e, (iii) em posição de Adjunto, com o verbo organizar e a expressão ter a sorte. Os dados ficam resumidos na Tabela 3 .

\begin{tabular}{|l|c|c|c|c|c|c|c|c|}
\hline Função $\downarrow$ Verbo $\rightarrow$ & Ter & Servir & Incluir & Organizar & Gostar & $\begin{array}{c}\text { Marcar } \\
\text { presença }\end{array}$ & $\begin{array}{c}\text { Ter a } \\
\text { sorte }\end{array}$ & Totais \\
\hline & & & & & & & & \\
\hline Sujeito & & & & & & 1 & & 1 \\
\hline CD & 2 & 2 & 1 & & & & & 5 \\
\hline COBL & & & & & 1 & & & 1 \\
\hline Adjunto Adverbial & & & & 1 & & & 1 & 2 \\
\hline Totais & 2 & 2 & 1 & 1 & 1 & 1 & 1 & 9 \\
\hline
\end{tabular}

Tabela 3. Perfil de comportamento na frase: verbos de que dependem.

Várias considerações poderão ser feitas em torno desta questão. Deixamos para já a constatação, muito genérica, da ausência de verbos da área de ser e da área de comerlexperimentar em contexto de relação direta com estas expressões referenciais.

Em contexto de dependência de nome (com estatuto de complemento ou modificador), os sintagmas coocorrem com itens muito variados e dispersos, como pode ver-se na Tabela 4 . 


\begin{tabular}{|l|c|c|c|c|c|c|c|c|c|}
\hline $\begin{array}{l}\text { Nome } \rightarrow \\
\text { Função } \downarrow\end{array}$ & $\begin{array}{c}\text { Encan- } \\
\text { tos }\end{array}$ & $\begin{array}{c}\text { Espé- } \\
\text { cimes }\end{array}$ & Pratos & $\begin{array}{c}\text { Corese } \\
\text { aromas }\end{array}$ & Pavilhão & Cultor & $\begin{array}{c}\text { Apreci- } \\
\text { adores }\end{array}$ & pesquisa & Totais \\
\hline $\begin{array}{l}\text { Cozinha } \\
\text { tradicional } \\
\text { portuguesa }\end{array}$ & 1 & 1 & 1 & 1 & 1 & 1 & & 6 \\
\hline $\begin{array}{l}\text { Comida } \\
\text { tradicional } \\
\text { portuguesa }\end{array}$ & 1 & & & & & & & & 1 \\
\hline $\begin{array}{l}\text { Receitas } \\
\text { tradicionais } \\
\text { portuguesas }\end{array}$ & & & & & & & & & 1 \\
\hline Totais & 1 & 1 & 1 & 1 & 1 & 1 & 1 & 1 & 8 \\
\hline
\end{tabular}

Tabela 4 - Perfil de comportamento na frase: nomes de que dependem.

\section{Perfil de comportamento na frase: adjetivações}

Considerámos, neste tópico, não só os casos em que o adjetivo incide diretamente nos SN em causa (por exemplo: boa comida tradicional portuguesa), como também os casos em que a adjetivação afeta diretamente outras estruturas da mesma frase com as quais os SN estabelecem relações relevantes (por exemplo: comida tradicional portuguesa, com uma apresentação mais requintada). $\mathrm{Na}$ tabela que resume estas ocorrências distinguimos, assim, adjetivação direta e adjetivação indireta.

O número de adjetivações diretas no corpus é muito reduzido. Registámos apenas 3 casos, com os adjetivos nova, boa e "recauchutados", atributos de, respetivamente, cozinha tradicional portuguesa, comida tradicional portuguesa e pratos tradicionais portugueses.

$\mathrm{Na}$ tabela que se segue, resumem-se estes primeiros dados:

\begin{tabular}{|l|l|c|c|c|c|}
\hline \multicolumn{1}{|c|}{ SN $\downarrow$} & \multicolumn{1}{|c|}{ Segmento } & \multicolumn{2}{c|}{ Adjetivação direta } & Totais \\
\hline $\begin{array}{l}\text { Cozinha tradicional } \\
\text { portuguesa }\end{array}$ & $\begin{array}{l}\text { terá no cardápio, essencialmente, } \\
\text { uma “nova cozinha tradicional } \\
\text { portuguesa" }\end{array}$ & 1 & Nova & Recauchutados & \\
\hline $\begin{array}{l}\text { Comida tradicional } \\
\text { portuguesa }\end{array}$ & $\begin{array}{l}\text { boa comida tradicional } \\
\text { portuguesa }\end{array}$ & 1 & & & 1 \\
\hline $\begin{array}{l}\text { Receitas tradicionais } \\
\text { portuguesas }\end{array}$ & $\begin{array}{l}\text { E se incluir os pratos tradicionais } \\
\text { portugueses “recauchutados" nas } \\
\text { ementas das seleç̧óes possa ser } \\
\text { tarefa difícil }\end{array}$ & & 1 & 1 \\
\hline Totais & & 1 & 1 & 1 & 3 \\
\hline
\end{tabular}

Tabela 5 - Perfil de comportamento na frase: adjetivações diretas. 
Ao sabor da sintaxe, a que sabe a tradição? Contribuição para o estudo do património linguístico da alimentação

As adjetivações "indiretas" são em número mais significativo e ocorrem em estruturas com as quais os $\mathrm{SN}$ estabelecem relações sintáticas muito diversificadas, com diferentes graus de proximidade. Os itens são também muito variados: para além de boa / melhor (com 2 ocorrências cada) e nova, há outros adjetivos (Tabela 6). Em todos os casos, a carga semântica dos adjetivos nos sintagmas contíguos parece afetar claramente os $\mathrm{SN}$ aqui em causa.

\begin{tabular}{|l|c|c|c|c|c|c|c|c|c|c|}
\hline SN & \multicolumn{7}{|c|}{ Adjetivação “indireta” } \\
\hline & $\begin{array}{c}\text { Boal } \\
\text { melhor }\end{array}$ & Nova & $\begin{array}{c}\text { Ousa- } \\
\text { das }\end{array}$ & $\begin{array}{c}\text { Requin- } \\
\text { tada }\end{array}$ & $\begin{array}{c}\text { Seguro e } \\
\text { conhecedor }\end{array}$ & Perfeito & Real & $\begin{array}{c}\text { Origi- } \\
\text { nal }\end{array}$ & $\begin{array}{c}\text { Afamadose e } \\
\text { afreguesados }\end{array}$ & Difícil \\
\hline $\begin{array}{l}\text { Comida } \\
\text { tradicional } \\
\text { portuguesa }\end{array}$ & 3 & & 1 & 1 & & & & & & \\
\hline $\begin{array}{l}\text { Cozinha } \\
\text { tradicional } \\
\text { portuguesa }\end{array}$ & 1 & & & & 1 & 1 & 1 & 1 & 1 & \\
\hline $\begin{array}{l}\text { Receitas } \\
\text { tradicionais } \\
\text { portuguesas }\end{array}$ & & & & & & & & & & 1 \\
\hline
\end{tabular}

Tabela 6 - Perfil de comportamento na frase: adjetivações indiretas.

Um contexto de maior proximidade é aquele em que a adjetivação afeta diretamente um sintagma coordenado (num dos casos, o adjetivo ocorre também no SN em análise):

R1235: Comecemos pelo restaurante D. Tonho, está na moda, sem dúvida, e pertence ao famoso Rui Veloso. Á́, para além da cozinha tradicional portuguesa e de um serviço perfeito, pode ter a sorte de esbarrar-se com o cantor portuense. noCOD_1090946: Adoro comer, nesta zona consigo encontrar os melhores

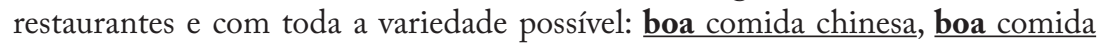
italiana e boa comida tradicional portuguesa.

Noutros casos, é o nome de que depende o SN (com o estatuto de modificador ou complemento) que surge com adjetivo:

J6329: O repasto que assinala esta manifestação do núcleo português da confraria terá lugar num hotel da capital, fazendo jus a alguns dos melhores pratos da cozinha tradicional portuguesa.

noCOD_1059017: Hernâni Machado é um cultor seguro e conhecedor da cozinha tradicional portuguesa.

J0033: Esta planta, lembre-se, desempenha um papel essencial no tempero dos maranhos, burulhões ou borlhões, um dos espécimes mais originais da cozinha tradicional portuguesa, infelizmente afastados das ementas dos restaurantes, mesmo da sua região de origem, que é a Beira Interior. 
Contabilizámos também adjetivações presentes em sintagmas preposicionais dependentes, direta ou indiretamente, dos SN em estudo:

J52989: "Teremos comida tradicional portuguesa, com uma apresentação mais requintada, na linha da nova cozinha portuguesa”, explicou Silva Carvalho.

Noutros contextos, os sintagmas em relação são codependentes do mesmo núcleo verbal, como é o caso da relação entre sujeito e CD no exemplo (aqui mediado por um pronome relativo):

J106052: São 70 anos a servir o público, primeiro ao balcão da taberna aberta pelos pais, a 1 de maio de 1926, na rua F. de M, que mais tarde se tornou num dos_mais afamados e afreguesados restaurantes lisboetas que servem cozinha tradicional portuguesa.

Um conjunto de outros exemplos configura possíveis interações dos SN com adjetivos em posições mais distantes e menos lineares:

J41253: Vindo da Alemanha, onde percorreu a Exposição Mundial de Hanôver, Jorge Sampaio aterrou em Portugal e, ao fim da tarde, esperava-o uma viagem ao país real através do artesanato, mais as cores e os aromas da cozinha tradicional portuguesa. noCOD_1070417: E se incluir os pratos tradicionais portugueses " recauchutados " nas ementas das selecções possa ser tarefa difícil, a intenção do chefe de cozinha da seleção nacional portuguesa Hélio Loureiro era servir de anfitrião aos colegas dos outros países, numa iniciativa pioneira que muito agradou aos "colegas de profissão e rivais no jogo».

noCOD_1090946: Adoro comer, nesta zona consigo encontrar os melhores restaurantes e com toda a variedade possível: boa comida chinesa, boa comida italiana e boa comida tradicional portuguesa.

noCOD_1054763: Alguns, já rendidos aos encantos da comida tradicional portuguesa, não hesitam em experimentar misturas mais ousadas.

\section{Perfil de comportamento na frase: redes de referências}

Uma outra análise que nos propomos fazer no âmbito do nosso estudo prende-se com as redes de relações que estes sintagmas estabelecem com outras expressões referenciais dentro do universo da frase. Neste sentido, distinguimos três grupos temáticos de expressões: (i) espaços, atividade(s) e atores - por exemplo, restaurante, restauração, chef, etc.; (ii) nomes de pratos e ingredientes - bacalhau, maranhos, etc.; e (iii) eventos e outras referências culturais - semana gastronómica, artesanato, etc.

$\mathrm{Na}$ Tabela 7, registam-se alguns exemplos mais relevantes: 
Ao sabor da sintaxe, a que sabe a tradição? Contribuição para o estudo do património linguístico da alimentação

\begin{tabular}{|c|c|c|c|}
\hline $\begin{array}{l}\text { Referências } \rightarrow \\
\text { SN } \downarrow\end{array}$ & $\begin{array}{c}\text { Espaços, atividade(s) } \\
\text { e atores } \\
\end{array}$ & $\begin{array}{c}\text { Pratos e } \\
\text { ingredientes }\end{array}$ & $\begin{array}{l}\text { Eventos e outras } \\
\text { referências culturais }\end{array}$ \\
\hline $\begin{array}{l}\text { Cozinha tradicional } \\
\text { portuguesa }\end{array}$ & $\begin{array}{c}\text { restaurante } \\
\text { (balcão da) taberna } \\
\text { restaurantes lisboetas } \\
\text { o Tavares, } \\
\text { chefJ. Figueiredo } \\
\text { repasto } \\
\text { cervejarias } \\
\text { tascas } \\
\end{array}$ & $\begin{array}{c}\text { planta } \\
\text { (tempero dos) } \\
\text { maranhos } \\
\text { ementas } \\
\text { cardápio } \\
\text { pratos }\end{array}$ & $\begin{array}{c}\text { semanas gastronómicas } \\
\text { núcleo português da } \\
\text { confraria Portugal } \\
\text { país real } \\
\text { artesanato } \\
\text { confrarias báquicas e } \\
\text { gastronómicas } \\
\text { cantor portuense } \\
\end{array}$ \\
\hline $\begin{array}{l}\text { Comida tradicional } \\
\text { portuguesa }\end{array}$ & $\begin{array}{l}\text { restauração } \\
\text { salão de chá }\end{array}$ & $\begin{array}{l}\text { misturas mais } \\
\text { ousadas } \\
\text { nova entrada } \\
\text { receitas } \\
\text { bacalhau }\end{array}$ & \\
\hline $\begin{array}{l}\text { Receitas tradicionais } \\
\text { portuguesas }\end{array}$ & $\begin{array}{l}\text { chef } \\
\text { a casa }\end{array}$ & $\begin{array}{c}\text { pratos antigos } \\
\text { cozinha lusitana } \\
\text { doçaria conventual }\end{array}$ & \\
\hline $\begin{array}{l}\text { Pratos tradicionais } \\
\text { portugueses }\end{array}$ & $\begin{array}{c}\text { restaurante } \\
\text { chefe de cozinha } \\
\text { colegas de profissão }\end{array}$ & & $\begin{array}{c}\text { regiões de Portugal } \\
\text { vendas de artesanato } \\
\text { seleçâo nacional } \\
\text { espetáculos de música } \\
\text { seleçôes }\end{array}$ \\
\hline
\end{tabular}

Tabela 7 - Perfil de comportamento na frase: redes de referências.

\section{Conclusões}

As teias de cumplicidades existentes na relação entre os alimentos (entendidos como matéria-prima), a alimentação (entendida como prática civilizadora) e a linguagem verbal (quer nas suas atualizações individuais, quer nas comunitárias) conseguiram finalmente ocupar, nos anos mais recentes, um lugar de destaque na inquirição das Ciências da Linguagem ${ }^{16}$ e no mundo académico. Entre inúmeras possibilidades, podemos estudá-las (i) como modo de construção linguística de identidades, (ii) como forma de revisitar o passado comum $^{17}$ e (iii) como base de análise de organização dos nossos comportamentos - observáveis ou não - em torno de rituais, de preferências, de gostos (também de natureza estética) e até de normas oficiais de saúde e de higiene ${ }^{18}$.

Propusemo-nos, com este estudo, traçar o perfil do comportamento na frase (enquanto unidade nuclear e estruturante do texto) dos sintagmas

${ }^{16}$ Numa breve sistematização, por exemplo, na Linguística, na Linguística Aplicada, na Sociolinguística, na Psicolinguística, na Análise Conversacional, na Etnolinguística, na Antropolinguística e nos estudos da comunicação virtual.

${ }^{17}$ Apesar de se tratar de óticas com intenções diversas, cf. Brandão (1981) e Carneiro (2003).

${ }^{18}$ Cf. Barthes 1993. 
cozinh a tradicional portuguesa, comida tradicional portuguesa, receitas tradicionais portuguesas e pratos tradicionais portugueses, vistos aqui, no seu conjunto, como representações linguístico-discursivas da tradição alimentar.

Ainda que embrionárias, as primeiras grandes conclusões parecem apontar para os seguintes aspetos:

1. Em primeiro lugar, é de salientar o facto de estes $\mathrm{SN}$ apresentarem apenas uma ocorrência em posição de sujeito (de frase ou oração subordinada). Este dado pode ser indicador de uma posição menos central ocupada por estas expressões na organização temático-informativa dos textos. Poderá ser relacionada com esta caraterística do comportamento dos sintagmas a ausência de casos de combinação com o verbo ser.

2. Observamos, por outro lado, que os contextos de dependência de verbo e os contextos de dependência de nome apresentam números muito próximos.

3. Em contexto de dependência de verbo, os sintagmas assumem essencialmente o estatuto de objeto (complemento direto). Em contexto de dependência de nome, assumem ora o papel de objeto (complemento de nome) ora o papel de "identificador" ou "restritor" da referência expressa no nome (modificador).

4. Uma última observação genérica que consideramos relevante destaca o sentido fortemente positivo das adjetivações copresentes na mesma unidade frásica, quer em contexto de incidência direta, quer em contexto de incidência (indireta) em espaços sintaticamente próximos.

\section{BibLIOGRAFIA}

Actas do XI Encontro Nacional da Associação Portuguesa de Linguística. (1995),Vol. I. Corpora. Maria Fernanda Bacelar do Nascimento, Maria Celeste Rodrigues, José Bettencourt Gonçalves (orgs.), Colibri, Lisboa (1996).

Algranti, M. (2002), Cozinha judaica: 5000 anos de história e gastronomia, Record, Rio de Janeiro.

Bacelar do Nascimento, M. F., Pereira, L. A. S. e Saramago, J., (2000), "Portuguese Corpora at CLUL", in Second International Conference on Language Resources and Evaluation - Proceedings. Volume II, Athens, 1603-1607.

Bacelar do Nascimento,M. F.(2000), "Corpus de Référence du Portugais Contemporain”, in M. Bilger (ed.). H., Corpus, méthodologie et applications linguistiques. Champion et Presses Universitaires de Perpignan, Paris, 25-30.

Bacelar do Nascimento, M. F., (2003), "O lugar do corpus na investigação linguística”, in A. Mendes, et alii (orgs.), Actas do XVIII Encontro da Associação Portuguesa de Linguística. Associação Portuguesa de Linguística e Edições Colibri, Lisboa.

Barthes, R.,(1993,1ª edição original,1961), "Pour une psycho-sociologie de l'alimentation contemporaine.", in Eric Marty (ed.), Roland Barthes: oeuvres completes. Tome I: 1942-1965. Éditions du Seuil, Paris, p. 924-933.

Brandão, C. R., (1981), Plantar, colher, comer: um estudo sobre o campesinato goiano, Edições Graal, Rio de Janeiro. 
Carneiro, H. S., (2003), Comida e sociedade. Uma história da alimentação, Campus, Rio de Janeiro.

Davsky, D., (2005), "La psicología social de la comida: una aproximación teórica y metodológica a la comida y las prácticas de la alimentación como secuencias narrativas." I. Cusien, (trad.), in Subjetividad y processos cognitivos. 7: 45-71.

Faria, R. L., (2007), A alma trocada, Colecção Asa Literatura, Edições Asa, Lisboa.

Gallian, D. M. C., (2007), “A desumanização do comer.”, Estudos Avançados 21 (60).

Habert, B., Nazarenko, A., Salem, A., (1997), Les linguistiques de corpus, Armand Colin, Paris.

Halliday, M. A. K., (1978), Language as Social Semiotic. The Social Interpretation of Language and Meaning, Edward Arnold Publishers, London.

Jovchelovitch, S. (2007), Knowledge in Context: Representations, Community and Culture, Routledge, New York/London.

Koch, I. G. V., (2001), "A referenciação como atividade cognitivo-discursiva e interacional.” Cad.Est.Ling. 41: 75-89.

Koch, I. G. V., (2008), “Como se constroem e reconstroem os objetos de discurso.”, in Revista Investigações: Linguística e Teoria Literária, 21: 2, 99-114.

London, J. (2000, 1st edition: 1904), The Sea-Wolf, Dover Publications, New York.

Long, L. (2004), "Learning to Listen to the Food: Recepies as Expression of Identity and Carriers of Memory", Food, Culture and Society: An International Journal of Multidisciplinary Research, 7: 1.

Marcuschi, L. A., (2001), "Anáfora indireta: o barco textual e suas âncoras.”, in Revista Letras, 56: 217-258.

Marks, G. (2005), Olive Trees and Honey: A Treasury of Vegetarian Recipes from Jerwish Communities around the World, Wiley, New Jersey.

Mondada, L., Dubois, D., (1995), “Construction des objets de discours et catégorisation: une approche des processus de référentiation”, in A. Berrendonner, M-J ReichlerBéguelin (eds), Du syntagme nominal aux objets-de discours. SN complexes, nominalisations, anaphores. Tranel, 23, Institute de Linguistique de l'Université de Neuchâtel, Neuchâtel.

Mondada, L., Dubois, D., (2003), “Construção dos objetos de discurso e categorização: uma abordagem dos processos de referenciação.”, in M. M. Cavalcante et al. (orgs.), Referenciação. Contexto, São Paulo, 17-52.

Raposo, E. B. P. et alii (eds), (2013), Gramática do português, vols. I \& II., Fundação Calouste Gulbenkian, Lisboa.

Sutton, D. E. (2001), Remembrance of Repasts: An Anthropology of Food and Memory, Berg, Oxford/New York. 